\title{
ANALISIS RENTABILITAS DAN PENYERAPAN TENAGA KERJA PADA USAHATANI LEBAH MADU APIS CERANA DI DESA BANJARANYAR KECAMATAN BANJARANYAR KABUPATEN CIAMIS
}

\author{
ANALYSIS OF PROFITABILITY AND LABOR ABSORPTION IN APIS CERANA \\ HONEY BEE FARMING IN BANJARANYAR VILLAGE BANJARANYAR SUB- \\ DISTRICT CIAMIS DISTRICT
}

\author{
SUDARMAN $^{1 *}$, DINI ROCHDIANI ${ }^{2}$, MUHAMAD NURDINYUSUF ${ }^{1}$ \\ ${ }^{1}$ Mahasiswa Fakultas Pertanian Universitas Galuh \\ ${ }^{2}$ Dosen Fakultas Pertanian Universitas Padjadjaran \\ *Email: sudarmandoanx@gmail.com
}

\begin{abstract}
ABSTRAK
Usaha budidaya lebah madu merupakan salah satu usaha yang memiliki prospek usaha yang baik. Penelitian ini bertujuan untuk mengetahui : 1) Besarnya biaya, penerimaan, pendapatan usahatani lebah madu dalam satu kali musim panen, 2) Besarnya nilai Rentabilitas Usahatani lebah madu dalam satu kali musim panen, dan 3) Banyaknya penyerapan tenaga kerja pada usahatani lebah madu dalam satu kali musim panen. Metode yang digunakan dalam penelitian ini adalah metode survai dengan menggunakan alat bantu kuisioner. Teknik penarikan sampel dilakukan secara sensus terhadap 60 orang anggota kelompok tani. Hasil penelitian menunjukan bahwa: 1) Besarnya rata-rata biaya total yang dikeluarkan pada usahatani lebah madu di Desa Banjaranyar Kecamatan Banjaranyar Kabupaten Ciamis per satu kali musim panen adalah Rp 1.287.607,19,- dan rata-rata penerimaan Rp 1.670.575,-. Sedangkan rata-rata pendapatan $\mathrm{Rp} 383.967,81,-$. 2) Nilai rentabilitas yang diperoleh pada usahatani lebah madu di Desa Banjaranyar Kecamatan Banjaranyar Kabupaten Ciamis per satu kali produksi adalah 29,74 persen dari modal yang dikeluarkan. 3) Penyerapan tenaga kerja yang di serap oleh usahatani lebah madu di Desa Banjaranyar Kecamatan Banjaranyar Kabupaten Ciamis adalah 8,35 persen dari tolal angkatan kerja.
\end{abstract}

Kata kunci : Biaya, rentabilitas, penyerapan tenaga kerja

\begin{abstract}
Honey bee cultivation is a business that has good business prospects. This study aims to determine: 1) The amount of cost, revenue, and income of honey bee farming in one harvest season, 2) The value of the profitability of honey bee farming in one harvest season, and 3) The amount of labor absorption in honey bee farming in one harvest times. The method used in this research is a survey method using a questionnaire tool. The sampling technique was carried out by means of a census by taking all 60 members of the farmer group. The results showed that: 1) The average amount of total costs incurred on honey bee farming in Banjaranyar Village, Banjaranyar District, Ciamis Regency per one harvest season is IDR 1.278.665,52, and the average income is IDR 1,670,575. -. Meanwhile, the average income is IDR 391.909,48. 2) The profitability value obtained in honey farming in Banjaranyar Village, Banjaranyar District, Ciamis Regency per one production time is 30,65 percent of the issued capital. 3) The absorption of labor absorbed by honey farming in Banjaranyar Village, Banjaranyar District, Ciamis Regency is 8.35 percent of the total labor force.
\end{abstract}

Keywords: cost, profitability, employment 


\section{PENDAHULUAN}

Pertanian merupakan sektor yang memiliki peranan penting dalam pembangunan di Indonesia. Pembangunan di sektor pertanian menjadi kunci bagi keberhasilan pembangunan ekonomi dan nasional. Salah satu aspek penting dalam pembangunan pertanian adalah sektor kehutanan dengan hasil hutan pada umumnya berupa kayu. Namun hasil hutan di Indonesia bukan hanya kayu saja akan tetapi terdapat pula hasil hutan bukan kayu salah satunya adalah madu yang merupakan hasil usaha budidaya lebah yang memiliki banyak manfaat untuk kesehatan bagi masyarakat dan juga dapat meningkatkan pendapatan bagi yang melakukan usaha tersebut untuk memenuhi kebutuhan individu petani dan anggota keluarga (Adalina, 2011)

Usaha budidaya lebah madu merupakan salah satu usaha yang memiliki prospek usaha yang baik. Keadaan alam Indonesia sangat cocok untuk usaha peternakan lebah madu karena Indonesia kaya akan ragam tanaman berbunga sebagai pakan bagi para lebah.

Setiap usaha yang dilakukan akan memerlukan biaya agar usahanya berjalan dengan lancar termasuk pada usahatani lebah madu apis cerana di desa banjaranyar. analisis biaya atau modal yang akan dikeluarkan baik biaya tenaga kerja atupun yang lainnya perlu diperhitungkan agar dapat diketahui biaya yang dikeluarkan serta laba yang akan didapatkan.

Adapun tujuan dari penelitian ini untuk mengetahui besarnya biaya, penerimaan dan pendapatan serta besarnya nilai rentabilitas dan penyerapan tenaga kerja pada usahatani lebah madu apis cerana di desa banjaranyar, kecamatan banjaranyar, kabupaten ciamis dalam satu kali musim panen.

\section{METODE PENELITIAN}

\section{Jenis Penelitian}

Penelitian ini dilakukan dengan menggunakan metode survei yang mengambil suatu kasus di Desa Banjaranyar, Kecamatan Banjaranyar, Kabupaten Ciamis. Menuru Nazir (2005) metode survai merupakan metode formal untuk memperoleh informasi yang sama dari orang atau berbagai kelompok yang ditempuh dengan kuisioner sebagai alat pengumpul data yang pokok.

\section{Teknik Pengumpulan Data}

Teknik pengumpulan data yang digunakan dalam penelitian ini meliputi data primer dan data sekunder. Data primer diperoleh dari hasil wawancara kepada 
petani madu secara langsung, dengan menggunakan daftar pertanyaan (kuesioner) yang telah dipersiapkan sebelumnya. Sedangkan data sekunder diperoleh dari dokumentasi yang dilakukan dengan teknik pengumpulan data tidak langsung ditujukan kepada subjek penelitian dan dari penelusuran pustaka/literatur maupun publikasi dari dinas atau instansi terkait.

Penarikan sampel Desa Banjaranyar, Kecamatan Banjaranyar, Kabupaten Ciamis diambil secara purposive menjadi lokasi penelitian karena mempunyai kelompok tani yang membudidayakan lebah madu dengan produksi madu tinggi. Responden ditentukan dengan cara sensus yaitu dengan mengambil seluruh anggota kelompok tani KTH (Kelompok Tani Hutan) Bina Lestari yaitu 60 orang.

\section{Rencana Analisis Data}

Untuk mengetahui besarnya biaya, penerimaan dan pendapatan pada usahatani

lebah madu digunakan analisis sebagai berikut :

1. Biaya Produksi (Suratiyah, 2006).

$\mathrm{TC}=\mathrm{TFC}$ TVC

Dimana $: \mathrm{TC}=$ Total Cost $($ Biaya Total).

TFC = Total Fixed Cost (Biaya Tetap Total).

TVC = Total Variable Cost (Biaya Variabel Total).

2. Penerimaan (Revenue) adalah hasil produksi dikalikan dengan harga jual produk pada saat panen (Soekartawi, 2002).

$\mathrm{TR}=\mathrm{Q} . \mathrm{P}$

Dimana :

$\mathrm{TR}=$ Penerimaan .

$\mathrm{Q}=$ Quantity (Jumlah Produksi).

$\mathrm{P}=$ Price (Harga)

3. Pendapatan/keuntungan adalah selisish antara penerimaan dengan biaya total (Soekartawi, 2002):

$\mathrm{Pd}=\mathrm{R}-\mathrm{C}$

Dimana :

$\mathrm{Pd}=$ Pendapatan

$\mathrm{R}=$ Penerimaan

$\mathrm{C}=$ Biaya Total

4. Analisis yang digunakan untuk mengetahui besarnya rentabilitas menggunakan rumus (Adiwicaksana, 2010), yaitu :

$$
\mathrm{R}=\frac{\mathrm{L}}{\mathrm{M}} \times 100 \%
$$

Dimana :

$\mathrm{R}=$ Rentabilitas suatu perusahaan yang menunjukan perbandingan antara laba dengan modal yang digunakan untuk menghasilkan laba $(\%)$.

$\mathrm{L}=$ Jumlah laba yang diperoleh pada periode tertentu $(\mathrm{Rp})$

$\mathrm{M}=$ Modal dari seluruh biaya yang digunakan untuk menghasilkan laba (Rp).

Analisis yang digunakan untuk mencari tingkat penyerapan tenaga kerja dalam usahatani lebah madu dapat dihitung dengan menggunakan rumus (Suratiyah, 2015), yaitu :

\begin{tabular}{llr} 
Penyerapan & $\begin{array}{l}\text { Jumlah tenaga kerja } \\
\mathrm{TK}=\end{array}$ & yang diserap dalam \\
& industri & 100 \\
\cline { 2 - 3 } & Angkatan & \\
& Kerja Desa &
\end{tabular}




\section{Tempat dan Waktu Penelitian}

Penelitian ini dilakukan di Desa Banjaranyar Kecamatan Banjaranyar Kabupaten Ciamis. Adapun penelitian ini dibagi dalam beberapa tahap, yaitu:

a) Tahap persiapan penelitian dilaksanakan pada bulan Januari sampai Maret 2020.

b) Tahap pelaksanaan penelitian dilaksanakan pada bulan April sampai Mei 2020.

c) Tahap pengolahan data dilaksanakan pada bulan Juni sampai Juli 2020.

Tahap penyusunan dan penulisan skripsi dilaksanakan pada bulan Agustus sampai dengan selesai.

\section{HASIL DAN PEMBAHASAN}

\section{A. Identitas Petani Ternak Lebah} Madu

\section{Umur Responden}

Petani yang melakukan ternak lebah madu berada pada usia antara 30-65 tahun. Umur Petani yang Berternak Madu di Desa Banjaranyar dapat dilihat pada tabel 1.

Tabel 1. Umur Petani yang Berternak Madu di Desa Banjaranyar Tahun 2020

\begin{tabular}{cccc}
\hline No & $\begin{array}{c}\text { Umur } \\
\text { (Tahun) }\end{array}$ & $\begin{array}{c}\text { Jumlah } \\
\text { (Orang) }\end{array}$ & $\begin{array}{c}\text { Persentase } \\
(\%)\end{array}$ \\
\hline 1 & $30-41$ & 23 & 38,33 \\
2 & $42-53$ & 20 & 33,34 \\
3 & $54-65$ & 17 & 28,33 \\
\hline \multicolumn{2}{c}{ Jumlah } & 60 & 100 \\
\hline
\end{tabular}

Hal ini menunjukan bahwa sebagian besar peternak adalah orang yang masih kuat fisiknya dalam melakukan usaha ternak madu. Dengan fisik yang kuat maka peternak akan mampu melakukan usaha ternak lebah madu dengan jumlah koloni banyak.

\section{Pengalaman Ternak Lebah Madu}

Pengalaman responden dalam mengusahakan ternak lebah madu yaitu sekitar 1-5 tahun. Pengalaman merupakan modal utama untuk keberhasilan dalam sebuah usaha, semakin lama pengalaman semakin tinggi keterampilan yang dimiliki dalam melaksanakan proses produksi, yaitu dengan mempelajari setiap permasalahan yang di alami sehingga akan lebih mampu dan mendapatkan cara untuk memecahkan dan menyelesaikan setiap permasalahan yang timbul di kemudian hari. Pengalaman Petani Dalam Berternak Lebah Madu dapat dilihat pada tabel 2 .

\begin{tabular}{cccc}
$\begin{array}{c}\text { Tabel 2. Pengalaman } \\
\text { Berternak Lebah } \\
\text { Banjaranyar } \\
\text { Banjaranyar }\end{array}$ & $\begin{array}{c}\text { Petani } \\
\text { Madu } \\
\text { Kecamatan }\end{array}$ & $\begin{array}{c}\text { Dalam } \\
\text { Desa }\end{array}$ \\
\hline No & $\begin{array}{c}\text { Pengalaman } \\
\text { Berusahatani } \\
\text { Madu }\end{array}$ & $\begin{array}{c}\text { Jumlah } \\
\text { (Orang) }\end{array}$ & $\begin{array}{c}\text { Persentase } \\
(\%)\end{array}$ \\
& & \\
\hline & (Tahun) & & \\
\hline 1 & $1-2$ & 30 & 50 \\
2 & 3 & 17 & 28,4 \\
3 & 4 & 8 & 13,3 \\
4 & 5 & 5 & 8,3 \\
\hline & Jumlah & 60 & 100 \\
\hline
\end{tabular}




\section{Tingkat Pendidikan Petani Ternak Lebah Madu}

Tingkat pendidikan peternak lebah madu akan mempengaruhi terhadap keberhasilan usahanya. Tingkat pendidikan akan mempengaruhi taraf hidup dan kemajuan, karena secara langsung maupun tidak langsung pendidikan akan mempengaruhi cara berfikirnya. Tingkat

Jurnal ilmiah mahasiswa AGROINFO GALUH

Volume 8, nomor 2, mei 2021

pendidikan yang tinggi diharapkan akan memudahkan dalam menerima dan menerapkan pengetahuan dan teknologi, sehingga akan menentukan keberhasilan suatu usaha. Tingkat Pendidikan Petani Ternak Lebah Madu dapat dilihat pada tabel 3 .

Tabel 3. Tingkat Pendidikan Petani Ternak Lebah Madu di Desa Banjaranyar Banjaranyar

\begin{tabular}{cccc}
\hline No & $\begin{array}{c}\text { Tingkat } \\
\text { Pendidikan }\end{array}$ & $\begin{array}{c}\text { Jumlah } \\
\text { (Orang) }\end{array}$ & $\begin{array}{c}\text { Persentase } \\
(\%)\end{array}$ \\
\hline 1 & SD & 46 & 76,7 \\
2 & SMP & 6 & 10 \\
3 & SMA & 7 & 11,7 \\
4 & Sarjana & 1 & 1,6 \\
\hline & Jumlah & 60 & 100 \\
\hline
\end{tabular}

\section{Tanggungan Keluarga}

Tanggungan keluarga adalah banyaknya anggota keluarga yang masih ditanggung oleh kepala keluarga yang terdiri dari istri, anak atau anggota keluarga lainnya yang menjadi tanggung jawab responden untuk memenuhi kebutuhan hidupnya. Jumlah tanggungan keluarga petani ternak madu di Desa Banjaranyar berkisar antara 1 sampai 3 orang. Untuk lebih jelasnya mengenai keadaan petani berdasarkan tanggungan keluarga dapat dilihat pada tabel 4.

Tabel 4. Keadaan Petani Ternak Lebah Madu Berdasarkan Tanggungan Keluarga di Desa Banjaranyar Tahun 2020

\begin{tabular}{cccc}
\hline No & $\begin{array}{c}\text { Jumlah } \\
\text { Tanggungan } \\
\text { Keluarga }\end{array}$ & $\begin{array}{c}\text { Jumlah } \\
\text { (Orang) }\end{array}$ & $\begin{array}{c}\text { Persentase } \\
(\%)\end{array}$ \\
\hline 1 & 1 & 12 & 20 \\
2 & 2 & 39 & 65 \\
3 & 3 & 9 & 15 \\
\hline & Jumlah & 60 & 100 \\
\hline
\end{tabular}

\section{B. Analisis Usahatani Ternak Madu di} Desa Banjaranyar

\section{Analisis Biaya}

Biaya produksi adalah modal yang digunakan dalam usaha dengan tujuan untuk menghasilkan produk yang dapat menghasilkan keuntungan. Biaya produksi tersebut disebut juga biaya total yang meliputi biaya tetap dan biaya variabel. Untuk rincian rata-rata biaya tetap dan biaya variabel usaha ternak lebah madu dapat dilihat pada tabel 5 . 
Tabel 13. Rata-Rata Biaya Produksi Usahatani Madu Per Satu Kali Musim Panen di Desa Banjaranyar Kecamatan Banjaranyar

\begin{tabular}{lrr}
\hline \multicolumn{1}{c}{ Komponen Biaya } & Nilai $(\mathrm{Rp})$ & Persentasi $(\%)$ \\
\hline a. Biaya Tetap & & \\
- Penyusutan Alat & $106.988,89$ & 8,37 \\
- Bunga Modal & $4.213,80$ & 0,33 \\
- PBB & $33.004,50$ & 2,58 \\
Jumlah & $144.207,19$ & \\
b. Biaya Variabel & & \\
- Biaya Sarana Produki & $1.027 .150,00$ & 80,33 \\
- Biaya Tenaga Kerja & $107.308,33$ & \\
Jumlah & $1.134 .458,33$ & 100 \\
\hline Jumlah total & $1.278 .665,52$ & \\
\hline
\end{tabular}

\section{Analisis Penerimaan dan Pendapatan}

Untuk menghasilkan penerimaan usahatani madu dilakukan dengan cara mengalikan jumlah produksi madu dengan harga pada saat produksi. Berdasarkan hasil penelitian diketaui produksi madu di Desa Banjaranyar adalah sebanyak 6,6823 kilogram dan harga pada saat penelitin adalah Rp 250.000,- per kilogram. Maka rata-rata penerimaan usahatani madu adalah Rp 1.670.575,- per satu kali musim panen.

Untuk mengetahui pendapatan usahatani madu dihitung dengan cara perbandingan antara penerimaan dengan biaya total yang dikeluarkan untuk melakukan usahatani madu. Jumlah penerimaan usahatani madu di Desa Banjaranyar berdasarkan hasil penelitian diketahui Rp 1.670.575,- dan biaya total yang dikeluarkan adalah $\mathrm{Rp} 1.278 .665,52,-$ - Maka rata-rata pendapatan usahatani madu adalah Rp 391.909,48,-- per satu kali musim panen.

\section{Rentabilitas Usahatani Madu}

Rentabilitas diketahui dengan cara perbandingan antara pendapatan dengan biaya total. Berdasarkan hasil penelitian diketaui bahwa pendapatan usahatani madu di Desa Banjaranyar adalah Rp 391.909,48,- dan biaya total yang dikeluarkan adalah $\mathrm{Rp} 1.278 .665,52,-$ per atu kali musim panen. Maka dengan demikian dapat dihitung nilai rentabilitas sebagai berikut :

$$
\begin{aligned}
\mathrm{R} & =\frac{L}{M} \times 100 \% \\
\mathrm{R} & =\frac{391.909,48}{1.278 .665,52} \times 100 \% \\
& =30,65 \%
\end{aligned}
$$

Hasil perhitungan menunjukkan bahwa nilai rentabilitas usahatani madu di Desa Banjaranyar Kecamatan Banjaranyar yaitu 30,65 persen dengan demikian usahatani madu tersebut dapat menghasilkan laba sebaesar 30,65 persen 
dari modal yang dikeluarkan dalam satu kali musim panen.

\section{Penyerapan tenaga kerja pada usahatani lebah madu}

Nilai penyerapan tenaga kerja diketahui dengan cara perbandingan antara jumlah tenaga kerja yang di serap yaitu sebanyak 279 orang dengan jumlah

angkatan kerja yaitu sebanyak 3.342 orang dikalikan dengan 100.

$$
\begin{aligned}
& \frac{\text { Jumlah tenaga kerja yang diserap }}{\text { Jumlah angkatan kerja }} \times 100 \% \\
& =\frac{279}{3.342} \times 100 \% \\
& =8,35 \%
\end{aligned}
$$

Hasil perhitungan memperlihatkan bahwa nilai penyerapan tenaga kerja usahatani madu di Desa Banjaranyar Kecamatan Banjaranyar adalah 8,35 persen, artinya usahatani madu telah mampu menyerap tenaga kerja 8,35 persen dari jumlah Angkatan kerja di Desa Banjaranyar Kecamatan Banjaranyar Kabupaten Ciamis dengan rata-rata jumlah tenaga kerja 4 orang.

\section{KESIMPULAN DAN SARAN}

\section{Kesimpulan}

Berdasarkan hasil dan pembahasan yang telah dilakukan dapat diambil keimpulan sebagai berikut :
1) Besarnya rata-rata biaya total yang dikeluarkan pada usahatani lebah madu di Desa Banjaranyar Kecamatan Banjaranyar Kabupaten Ciamis per satu kali musim panen adalah $\mathrm{Rp}$ 1.278.665,52,- dan rata-rata penerimaan $\quad \mathrm{Rp} \quad 1.670 .575,-$. Sedangkan rata-rata pendapatan $\mathrm{Rp}$ $391.909,48,-$.

2) Nilai rentabilitas yang diperoleh pada usahatani madu di Desa banjaranyar Kecamatan banjaranyar Kabupaten Ciamis per satu kali produksi adalah 30,65 persen dari modal yang dikeluarkan.

3) Penyerapan tenaga kerja yang di serap oleh usahatani madu di Desa banjaranyar Kecamatan banjaranyar Kabupaten Ciamis adalah 8,35 persen dari tolal angkatan kerja.

\section{Saran}

Berdasarkan pembahasan dan kesimpulan, maka usaha tersebut perlu dikembangkan. Petani ternak madu disarankan meningkatkan skala usaha tersebut dengan cara memperbanyak jumlah stup dan jumlah koloni yang di budidayakan agar menghasilkan produksi madu lebih banyak guna untuk dapat menyerap tenaga kerja yang lebih banyak lagi. 


\section{DAFTAR PUSTAKA}

Muhammad, Faddel. 2018. Persepsi petani dan analisis pendapatan usaha budidaya lebah madu di desa buana sakti kecamatan batanghari kabupaten lampung timur (Skripsi).

Filly, Novita Niarsari. 2018. Kontribusi usaha budidaya lebah madu terhadap pendapatan dan kesejahteraan petani lebah madu desa buana sakti kecamatan batanghari kabupaten lampung timur (Skripsi).

Subagja, Rajab. Dini Rochdiani. dan Muhamad Nurdin Yusuf. 2017. Penetapan harga pokok penjualan pada usahatani kedelai (glycine max l.) (suatu kasus di desa bantar kalong kecamatan cipatujah kabupaten tasikmalaya). Jurnal Ilmiah Mahasiswa AGROINFO GALUH Volume 4 Nomor 3, September 2017:
402-407

Hermanto Dedi Herdiansah S. dan Tito Hardiyanto. 2014. Analisis rentabilitas dan penyerapan tenaga kerja pada agroindustri gula kelapa (suatu kasus di desa bantar kecamatan wanareja kabupaten cilacap). Jurnal Ilmiah Mahasiswa AGROINFO GALUH Volume 2 Nomor 1, September 2015: 9-14

Aryani, Linda. Soetoro. dan Zulfikar Noormansyah. 2017. Rentabilitas dan penyerapan tenaga kerja pada agroindustri nata de coco (studi kasus

pada perusahaan nata de coco "family de coco" di desa tambakreja kecamatan kedungreja kabupaten cilacap. Jurnal Ilmiah Mahasiswa AGROINFO GALUH Volume 4 Nomor 2, Januari 2018: 743-747 